
Dopant-Free Hole Transporting Material for Efficient and Stable

\title{
Perovskite Solar Cells
}

4 Hong Duc Pham, ${ }^{a} \dagger$ Kazuma Hayasake, ${ }^{b}$ Jinhyun Kim, ${ }^{c}$ Thu Trang Do, ${ }^{a}$ Hiroyuki Matsui, ${ }^{b}$

5 Sergei Manzhos, ${ }^{d}$ Krishna Feron, ${ }^{e, f}$ Shizuo Tokito, ${ }^{b}$ Trystan Watson, ${ }^{g}$ Wing Chung Tsoi, ${ }^{g}$

6 Nunzio Motta, ${ }^{a}$ James R. Durrant, ${ }^{c, g}$ Sagar Motilal Jain, ${ }^{g^{*}} \uparrow$ Prashant Sonar ${ }^{a^{*}}$

7 a. Institute of Future Environment and School of Chemistry, Physics and Mechanical

8 Engineering, Queensland University of Technology (QUT), 2 George Street, Brisbane, QLD-

9 4001, Australia.

10 b. Research Center for Organic Electronics (ROEL), Yamagata University, 4-3-16 Jonan, 11 Yonezawa, Yamagata 992-8510, Japan.

12 c. Department of Chemistry and Centre for Plastic Electronics, Imperial College London, 13 Exhibition Road, London SW7 2AZ, United Kingdom.

14 d. Department of Mechanical Engineering, Faculty of Engineering, National University of 15 Singapore.

16 e. CSIRO Energy Centre, NSW-2304, Australia.

17 f. Centre for Organic Electronics, University of Newcastle, Callaghan, NSW 2308, Australia.

18 g. SPECIFIC, College of Engineering, Swansea University Bay Campus, Fabian Way, SA1

19 8EN Swansea, United Kingdom.

$20 \uparrow$ These authors, H. D. P and S. M. J contributed equally to the work.

21 Electronic Supplementary Information (ESI) available: [details of any supplementary 22 information available should be included here]. See DOI: 10.1039/x0xx00000x 
27 Perovskite solar cell (PSCs) technology has made a tremendous impact in the solar cell 28 community due to their exceptional performance, as the power conversion efficiency (PCE) 29 surged to world record $22 \%$ within just last few years. Despite this high efficiency value, the 30 commercialization of PSCs for large area applications at affordable prices is still pending due 31 to the low stability of devices in ambient atmospheric conditions and a very high cost of the 32 hole transporting materials (HTM) used as the charge transporting layer in such devices. To 33 cope with these challenges, the use of cheap HTMs can play a dual role in terms of lowering 34 the overall cost of the perovskite technology as well as protecting the perovskite layer to 35 achieve higher stability. In order to achieve these goals, various new organic hole 36 transporting materials (HTMs) have been proposed. In this work we use a unique and novel 37 anthanthrone (ANT) dye as a conjugated core building block and an affordable moiety to 38 synthesize a new HTM. The commercially available dye was functionalized with an extended 39 diphenylamine (DPA) end capping group. The newly developed HTM, named DPA-ANT40 DPA, was one-step synthesized and used successfully in mesoporous perovskite solar cell 41 devices, achieving a PCE of $11.5 \%$ under 1 sun condition with impressive stability. The 42 obtained device efficiency is amongst the highest, as per D-A-D molecular design and low 43 band gap concern. Such kind of low cost HTM based on inexpensive starting precursor 44 anthanthrone dye paves the way for economical and large-scale production of stable 45 perovskite solar cells. 


\section{Introduction}

48 The number of potentially economic solar cell technologies is increasing every year, in search of the Holy Grail of maximum conversion efficiency and minimum production cost. In the area of low cost solar cells, which includes as organic solar cells and dye sensitized solar cells (DSSC), organic-inorganic halide perovskite solar cells (PSCs) have gained much attention from the scientific community as scientists have been able to quickly achieve record performances, unparalleled in organic and DSSC. After the first breakthrough in 2013, the power conversion energy (PCE) for PSCs achieved a value of $22.1 \%$, ${ }^{1,2}$ very close to that of traditional silicon solar cells. Nevertheless, a few major obstacles are yet to be addressed before the commercial application of this technology. The first challenge is to improve the stability of the solar cells. The second one is how to enhance the performance in terms of PCE. The hole transporting layer (HTL) plays an extremely important role in both stability and performance of the perovskite solar cells. It improves the device stability by preventing the contact of the active perovskite layer with the metal electrode, blocking moisture and oxygen penetration. ${ }^{3}$ HTL is also instrumental in suppressing charge recombination allowing to achieve a higher open-circuit photovoltage $\left(V_{o c}\right)$, which leads to greater efficiency. ${ }^{4-}$ ${ }^{6}$ One of the key components responsible for the high cost of perovskite solar cells, is the hole transporting materials (HTL): in fact the most efficient and widely used HTL is the molecule: 2, 2', 7, 7'-tetrakis-( $N, N$-di- $p$-methoxyphenylamine)-9,9'-spirobifluorene (Spiro-OMeTAD). Unfortunately, the very high cost of the Spiro-OMeTAD molecule (400 USD per gram) limit the large scale production of perovskite solar cells. In order to make this technology more economical viable, there is a great need to find alternative HTLs with lower cost, simple synthesis, which would also be easily scalable and which can achieve equal or higher performance than the Spiro-OMeTAD. Currently, several economical organic hole transporting materials (HTMs) employed in PSCs show respectable efficiency and higher stability compared to SpiroOMeTAD. Among them, small molecular HTMs are advantageous compared to polymeric counterparts because of their high purity, defined molecular structure, promising yield, and better batch-to-batch reproducibility. ${ }^{7-9}$

In the group of small molecules, abundant rational molecular design strategies, including donor- $\pi$-donor (D- $\pi-\mathrm{D})$, acceptor-donor-acceptor (A-D-A) and donor- $\pi$ acceptor (D- $\pi-A)$ moieties, have been intensively used for synthesis. Perovskite 
80

81

82

83

84

85

86

87

88

89

90

91

92

devices with higher performance and better stability have been fabricated successfully using such HTMs. For example, (E)-4',4"'-(ethene-1,2-diyl)bis( $N, N$-bis(4methoxyphenyl)-[1",1"'-biphenyl]-4-amine) (TPA-BPV-TPA) (16.42\%), ${ }^{10} \quad 2^{\prime}, 7^{\prime}-$ bis(bis(4-methoxyphenyl)amino)spiro[cyclopenta[2,1-b:3,4-b]dithiophene-4,90fluorene]

(FDT) $(20.2 \%){ }^{11}$ $N$-(4-(9H-carbazol-9-yl)phenyl)-7-(4-(bis(4methoxyphenyl)amino)phenyl)- $N$-(7-(4-(bis(4-methoxyphenyl)amino)phenyl)-9,9dioctyl-9H-fluoren-2-yl)-9,9-dioctyl-9H-fluoren-2-amine (CzPAF-TPA) $(15.71 \%){ }^{12}$ 4,4'-(5,5'-(7,7'-(5,5'-(4,8-bis((2-ethylhexyl)oxy)benzo[1,2-b:4,5-b']dithiophene-2,6diyl)bis(3-hexylthiophene-5,2-diyl))bis(benzo[c][1,2,5]thiadiazole-7,4-diyl))bis(4hexyl-thiophene-5,2-diyl))bis(1-(2-ethylhexyl)pyridin-1-ium) bis(trifluoromethane sulfonimide) (M7-TFSI) (17.4\%), ${ }^{13}$ and 2,2',2"-(((5,10,15-trihexyl-10,15-dihydro-5Hdiindolo[3,2-a:3',2'-c] carbazole-3,8,13-triyl)tris(3,3'-dihexyl-[2,2':5',2'-terthiophene]5",5-diyl))tris(methanylylidene))trimalononitrile (KR321) (19.03\%). ${ }^{14}$ These HTMs can lead an efficiency in the range of $16-20 \%$. However, there are few new HTMs based on D-A-D structure reported until now, including 4,4'-(1,3,4-Oxadiazole-2,5diyl)bis( $N, N$-bis(4-methoxyphenyl)aniline) (H1), ${ }^{15}$ $4,4^{\prime}-(5,6-$ dimethoxybenzo[c][1,2,5]oxadiazole-4,7-diyl)bis( $N, N$-bis(4-methoxyphenyl)aniline) (BTPA-3), $\left(9,9^{\prime}-((\right.$ benzo[c] $[1,2,5]$ thiadiazole-4,7-diyl)bis $(4,1-$ phenylene)) $\operatorname{bis}\left(N^{3}, N^{3}, N^{6}, N^{6}\right.$-tetrakis(4-methoxyphenyl)-9H-carbazole-3,6-diamine) $\left(J_{Y 5}\right)^{16} \quad$ and $\quad\left(9,9^{\prime}-((5-f l u o r o b e n z o[c][1,2,5]\right.$ thiadiazole-4,7-diyl)bis(4,1phenylene))bis $\left(N^{3}, N^{3}, N^{6}, N^{6}\right.$-tetrakis(4-methoxyphenyl)-9H-carbazole-3,6-diamine) (JY6). ${ }^{17}$ The D-A-D structure has been designed by introducing an electron-deficient unit as the core with two strong electron-rich end-capping groups in order to obtain a deeper highest-occupied molecular orbital (HOMO) level, thereby improving the $V_{o c}{ }^{18}$ This strategy is expected to result in a higher PCE. ${ }^{5,10,19-21}$ In addition, compared to the $\mathrm{D}-\pi-\mathrm{D}$ type molecules, the intramolecular charge transfer (ICT) from the electrondonating unit to the electron-withdrawing unit can be boosted via the D-A-D one. ${ }^{6}$

In this work, we report one-step facile synthesis of a novel dopant-free D-A-D HTM based on a low cost anthanthrone (ANT) dye as the core and diphenylamine (DPA) as an efficient end-capping conjugated building block. The compound, namely 4,10-bis(bis(4-methoxyphenyl)amino)naphtho[7,8,1,2,3-nopqr]tetraphene-6,12-dione (DPA-ANT-DPA) is synthesized using standard Buchwald coupling between the halogenated derivative and the amine group; the synthesis details are shown in Scheme 
113 1. In this D-A-D type structure, 4,10-dibromoanthanthrone, named as VAT Orange 3

114 (Compound 1 in Scheme 1) low cost starting precursor was introduced as a strong 115 electron-withdrawing ketone unit in the core due to its $\pi$-conjugated nature and a large

116 conjugated planar structure. ${ }^{22-24}$ This is profitable for obtaining a low-lying HOMO 117 energy level, ${ }^{25}$ improving intermolecular interactions such as $\pi-\pi$ interactions ${ }^{22}$ and 118 achieving the high performance of organic optoelectronic devices. ${ }^{25}$

\section{Results and Discussion}

120 The synthesis of DPA-ANT-DPA is straightforward and follows Buchwald-Hartwig coupling 121 reaction. Compound 1 and 2 were mixed with [1,1'-Bis(diphenylphosphino)ferrocene] 122 dichloropalladium(II) $\left[\mathrm{PdCl}_{2}\right.$ (dppf)] catalyst at $90{ }^{\circ} \mathrm{C}$ for $24 \mathrm{~h}$ in anhydrous toluene solvent as 123 the earlier attempt. ${ }^{26}$ After purification by column chromatography, the yield of the reaction 124 was found to be of $80 \%$, leading to potential large-scale application in the future. The purity 125 was confirmed by proton and carbon NMR spectroscopy, the results of which are shown in 126 Fig. S1 (Supporting Information, ESI†). The synthetic procedure is detailed in the ESI $\uparrow$. The 127 material exhibited good solubility in most common organic solvents such as chloroform, 128 dichloromethane and chlorobenzene.

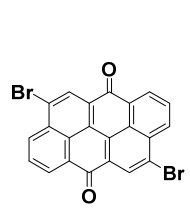

(1)

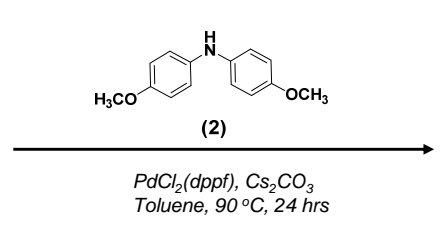
Toluene, $90^{\circ} \mathrm{C}, 24 \mathrm{hrs}$

Scheme 1. A single-step synthetic route for DPA-ANT-DPA and the geometrical configuration (front and side view).

To gain insight into the electronic structure of this material, density functional theory (DFT) calculations were performed at the B3LYP level of theory using the basis set 6$31 \mathrm{~g}+(\mathrm{d}, \mathrm{p}) .{ }^{27-29}$ As shown in Fig. 1a, while the electron density of the HOMO is fully delocalized over the entire molecules, the lowest unoccupied molecular orbital (LUMO) is primarily distributed over the $\pi$-conjugated system through the ANT core. According to DFT calculations, the HOMO and LUMO value are assessed to be $-4.79 \mathrm{eV}$ and $-3.01 \mathrm{eV}$ respectively. As a result, the band gap is found to be of $1.78 \mathrm{eV}$. In addition, the optical 
139 absorption maxima were at $892 \mathrm{~nm}$, resulting to the optical band gap of $1.39 \mathrm{eV}$. The DFT140 calculated data differs slightly from the experimental values due to the gaseous state 141 assumptions, but the result is still in a good agreement (Table 1).

(a)

LUMO: $-\mathbf{3 . 0 1} \mathrm{eV}$

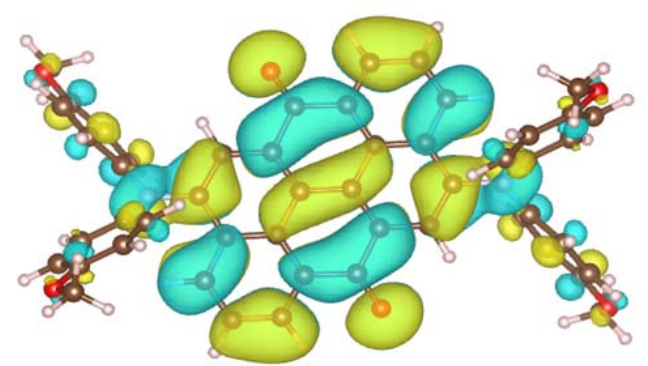

(b)

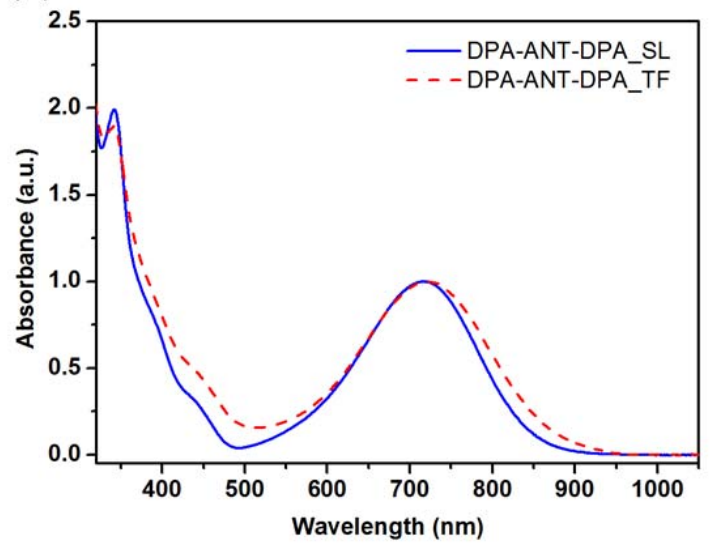

HOMO: $-4.79 \mathrm{eV}$

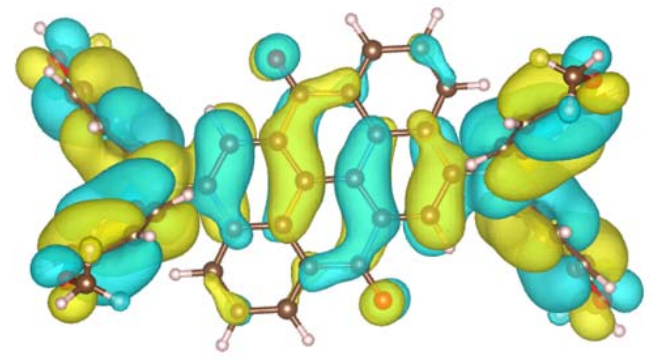

(c)

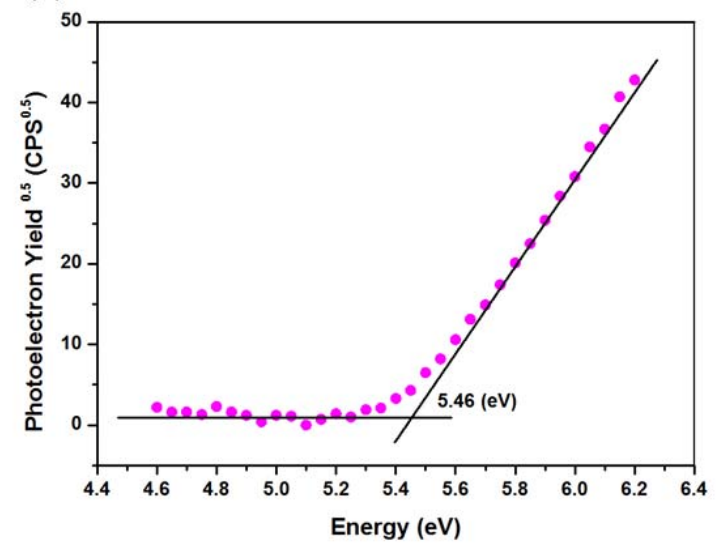

143 Fig. 1 (a) The calculated isosurfaces of electron density of HOMO and LUMO, (b) UV-Vis

144 absorption spectra in CF solutions (solid line) and films (dash line), (c) Photoelectron

145 spectroscopy in air (PESA) spectra of DPA-ANT-DPA.

146 The absorption of DPA-ANT-DPA in chloroform solution and in thin film on glass were 147 measured and shown in Fig. 1b. All the data is listed in Table 1. In the low wavelength 148 region, DPA-ANT-DPA reveals absorption maxima at $344 \mathrm{~nm}$ for the solution and $343 \mathrm{~nm}$ 149 for thin film respectively. Meanwhile, it shows broaden absorption in the visible range with maxima peak at $717 \mathrm{~nm}$ in solution and $724 \mathrm{~nm}$ in solid-state film respectively. The 151 electronic absorption in the near-infrared (NIR) region is attributed with the ICT band due to 152 the introduction of strong electron donating DPA end capping units and strong electron 153 accepting ANT core. ${ }^{30,31}$ The slight red shift of the absorption band in films compared with 154 solution indicates very weak intermolecular interactions in the solid state. Such weak solid- 
155 state interaction is also arising due to the presence of two distorted phenylene units. Such 156 propeller structure could be beneficial to form a better interface with three dimensional 157 photoactive perovskite layers in the devices, which can promote charge transport effectively. 158 The optical band gap of DPA-ANT-DPA compound, calculated using the solid-state 159 absorption onset values at $869 \mathrm{~nm}$, is $1.43 \mathrm{eV}$. This low band gap implies a strong 160 intramolecular D-A interaction in relative to the amine and quinone units as mentioned 161 previously. ${ }^{26}$ To the best of authors knowledge, it is the lowest band gap HTM for PSCs 162 compared to other low band gap HTMs $(1.47-1.50 \mathrm{eV})$ reported previously. ${ }^{30,32,33}$

163 Table 1 Thermal, optical and electrochemical properties of DPA-ANT-DPA.

\begin{tabular}{|c|c|c|c|c|c|c|c|c|c|c|}
\hline \multirow{2}{*}{ HTMs } & \multicolumn{2}{|c|}{$\lambda_{\max }(\mathrm{nm})$} & \multirow{2}{*}{$\begin{array}{l}\lambda_{\text {onset }} \\
(\mathrm{nm})\end{array}$} & $\begin{array}{c}E_{\mathrm{HOMO}}{ }^{\mathrm{d})} \\
(\mathrm{eV})\end{array}$ & \multirow{2}{*}{$\begin{array}{c}E_{\text {LUMO }}{ }^{\mathrm{d})} \\
(\mathrm{eV})\end{array}$} & \multirow{2}{*}{$\begin{array}{c}\mathrm{T}_{\mathrm{d}} \\
\left({ }^{\circ} \mathrm{C}\right)\end{array}$} & \multirow{2}{*}{$\begin{array}{c}\mathrm{T}_{\mathrm{g}} \\
\left({ }^{\circ} \mathrm{C}\right) \\
\end{array}$} & \multirow{2}{*}{$\begin{array}{c}\mathrm{T}_{\mathrm{c}} \\
\left({ }^{\circ} \mathrm{C}\right) \\
\end{array}$} & \multirow{2}{*}{$\begin{array}{c}\mathrm{T}_{\mathrm{m}} \\
\left({ }^{\circ} \mathrm{C}\right) \\
\end{array}$} & \multirow{2}{*}{$\begin{array}{c}\mu^{\mathrm{f})} \\
\left(\mathrm{cm}^{2} V^{-1} \mathrm{~s}^{-1}\right)\end{array}$} \\
\hline & Solution $^{\text {a) }}$ & Film $^{\text {b) }}$ & & $\begin{array}{c}E_{g}^{\left.o p t_{\mathrm{c}}\right)} \\
(\mathrm{eV})\end{array}$ & & & & & & \\
\hline $\begin{array}{c}\text { DPA-ANT- } \\
\text { DPA }\end{array}$ & 292 & 294 & 869 & -5.46 & -4.03 & 377 & 148 & 244 & 294 & $1 \times 10^{-4}$ \\
\hline \multicolumn{11}{|c|}{$\begin{array}{l}\text { a) Absorption spectrum was measured in chloroform }(\mathrm{CF}) \text { solution; }{ }^{b)} \text { Film was prepared by spin-coating an } \mathrm{CF} \\
\text { solution containing the sample onto glass substrate at a spin speed of } 1000 \mathrm{rpm} \text { at room temperature; }{ }^{c)} \text { Optical } \\
\text { bandgap was calculated from the formula of } 1240 / \lambda_{\text {onset }} ;{ }^{d)} \text { The oxidation potential was also measured by } \\
\text { photoelectron spectroscopy in air (PESA); } E_{\mathrm{LUMO}}{ }^{\mathrm{PESA}}=E_{\mathrm{HOMO}}{ }^{\mathrm{PESA}}+E_{g}^{o p t} ;{ }^{e)} \text { Oxidation potential of the material }\end{array}$} \\
\hline
\end{tabular}

171 In this work we determine the HOMO value of DPA-ANT-DPA experimentally using two 172 methods such as photoelectron spectroscopy in air (PESA) (Fig. 1c) and cyclic voltammetry 173 (CV) respectively (Fig. S2, ESI† ). All these parameters are shown in Table 1. The HOMO 174 value of DPA-ANT-DPA is estimated to be $-5.46 \mathrm{eV}$, being similar to the valence band 175 maximum (VBM) of the perovskite layer. The reduced energy gap between the HTL and the 176 active layer guarantees a high valued for of $V_{o c}$ and also keeps efficient hole extraction. 177 Meanwhile, the respective LUMO level of this compound was estimated, based on $E_{\mathrm{LUMO}}$ $178=E_{\mathrm{HOMO}}+\boldsymbol{E}_{\boldsymbol{g}}^{\boldsymbol{o p t}}$, to be found of $-4.03 \mathrm{eV}$. This low-lying LUMO energy level is below the 179 conduction band minimum (CBM) of the perovskite, which allows part of undesired electron 180 transport to occur and then cause to the low efficiency. While the LUMO value obtained by $181 \mathrm{CV}$ data is in consistent with the calculation one from PESA data, the HOMO values from 182 both techniques are slightly different. This may be caused by the energy values of sample in $183 \mathrm{CV}$ technique which was performed in dichloromethane solution with tetrabutylammonium 
184 hexafluorophosphate. Whereas, in PESA, the sample is deposited in thin film and then 185 exposed to ultraviolet light with certain intensity in air. The HOMO energy value data from 186 the PESA technique is more relevant since the actual devices in solid state and the PESA 187 measurement also performed in thin film form.

188 The thermal properties of DPA-ANT-DPA were determined by using thermogravimetric 189 analysis (TGA) and differential scanning calorimetry (DSC), which are shown in Fig. S3 190 (ESI $\dagger$ ) and summarized in Table 1. According to the TGA curve, this compound has an 191 extremely good thermal stability, and is stable up to $377{ }^{\circ} \mathrm{C}$. The thermal transitions were 192 investigated by DSC with two scan cycles. The melting temperature $\left(\mathrm{T}_{\mathrm{m}}\right)\left(294{ }^{\circ} \mathrm{C}\right)$ is 193 observed during the first and second heating scans whereas the glass transition $\left(\mathrm{T}_{\mathrm{g}}\right)\left(148{ }^{\circ} \mathrm{C}\right)$ 194 is only noticed during the second heating scan. Furthermore, the crystallization temperature $195\left(\mathrm{~T}_{\mathrm{c}}\right)$ is witnessed at $244{ }^{\circ} \mathrm{C}$ during the second heating scan. It turns out that the material has 196 some crystalline phases and this might be arising from donor-acceptor interaction and fused 197 core nature of ANT conjugated building block. ${ }^{34}$ This is in good agreement with the 198 observation of the needle-like crystals' formation during drying process of DPA-ANT-DPA 199 solution in the glass tube (Fig. S4, ESI $\dagger$ ). Meanwhile, there is no crystallization peaks 200 perceived during the cooling step. Furthermore, X-ray diffraction (XRD) was performed with 201 the result shown in Fig. S5 (ESI $\dagger$ ). The primary intense peak at $2 \theta=9.34^{\circ}$ was observed, 202 leading to a d-spacing (the lamellar repeating distance between the compound chains) of 1.1 203 nm calculated by using Bragg equation.

(a)

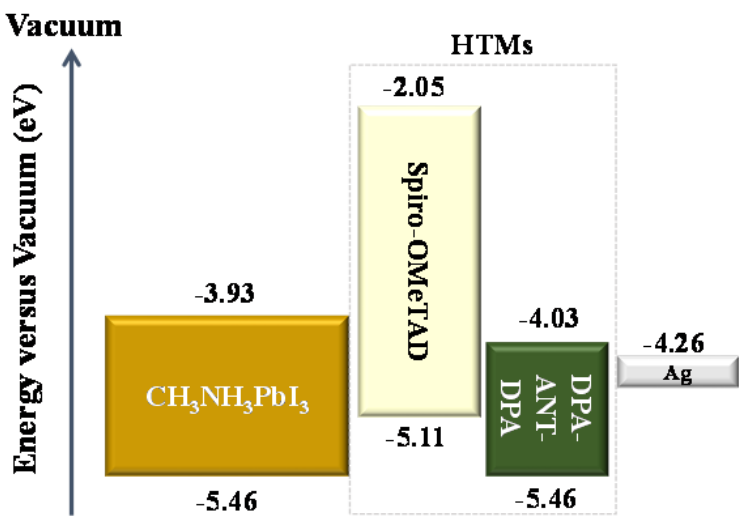

(b)

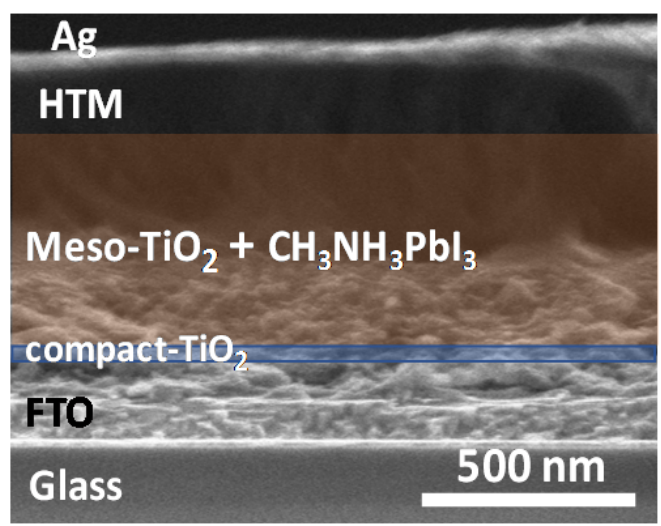

206 Fig. 2 (a) Energy level diagrams, (b) Cross-sectional scanning electron microscopy image of 207 PSC of DPA-ANT-DPA. 
209 In order to evaluate the effect of such crystalline phases on the charge carrier transport, we 210 used DPA-ANT-DPA material as an active layer in organic field-effect transistor (OFET) 211 devices using bottom gate top contact devices. The OFET device fabrication is described in 212 ESI†. Its data is shown in Table 1 and illustrated in Fig. S6 (ESI†). The hole mobility of 213 DPA-ANT-DPA was calculated using output and transfer characteristics. The mobility of 214 DPA-ANT-DPA was calculated to be $2.6 \times 10^{-4} \mathrm{~cm}^{2} \mathrm{~V}^{-1} \mathrm{~s}^{-1}$, which is higher than that of Spiro215 OMeTAD $\left(\mu=1.69 \times 10^{-6}-2.3 \times 10^{-5} \mathrm{~cm}^{2} \mathrm{~V}^{-1} \mathrm{~s}^{-1}\right)^{35,36}$ measured with a similar experimental 216 technique (using OFET devices). Furthermore, we measured and compared the hole mobility 217 of our newly developed DPA-ANT-DPA and of the traditional Spiro-OMeTAD hole 218 transport layers (Fig. S7, ESI†) using hole only space charge limited current method using 219 identical conditions. The hole mobility for DPA-ANT-DPA is $1 \times 10^{-4} \mathrm{~cm}^{2} \mathrm{~V}^{-1} \mathrm{~s}^{-1}$ whereas for 220 Spiro-OMeTAD it is $1.6 \times 10^{-4}$ respectively measured by SCLC method. As per solar cell 221 devices concern, SCLC measurement is most relevant techniques which give correct charge 222 carrier mobility since the charge transport occurs vertically. The details of sample preparation and SCLC measurement can be found in supporting information (ESI $\dagger$ ). Bopth OFET and SCLC techniques confirms the better charge carrier mobility of our newly developed hole transport layers DPA-ANT-DPA .

After the optical, thermal and electrochemical characterization of the new small molecule, the DPA-ANT-DPA layer was fabricated within the conventional perovskite devices processing as HTM, with the main aim to study the effect of the hole transport layers on the device performance. PSC devices with the $\mathrm{FTO} /$ compact- $\mathrm{TiO}_{2} / \mathrm{Mesoporous}^{-}$ $\mathrm{TiO}_{2} / \mathrm{CH}_{3} \mathrm{NH}_{3} \mathrm{PbI}_{3} / \mathrm{HTL} / \mathrm{Ag}$ device architecture were fabricated as per previously reported procedure. $^{37}$ The configuration of mesoscopic heterojunction perovskite solar cells was characterized by the cross-sectional scanning electron microscopy (SEM) and shown in Fig. 2b. A dense compact- $\mathrm{TiO}_{2}$ blocking layer $(\sim 30$ to $40 \mathrm{~nm})$ is first deposited on the FTO substrate by spray pyrolysis, while a mesoporous n-type mp- $\mathrm{TiO}_{2}$ layer is formed by spincoating of diluted $\mathrm{TiO}_{2}$ paste. The $\mathrm{CH}_{3} \mathrm{NH}_{3} \mathrm{PbI}_{3}$ absorber layer was then applied on mesoporous $\mathrm{TiO}_{2}$ by solvent engineering reported by Seok's group. ${ }^{37}$

237 The perovskite solution was prepared as per standard procedure and details can be found 238 in the supporting information (ESI $\dagger$ ). Around $120 \mathrm{~nm}$ thick HTLs were applied to the top $239 \mathrm{CH}_{3} \mathrm{NH}_{3} \mathrm{PbI}_{3}$ layer by spin coating. Finally, silver as a counter electrode was deposited by 240 thermal evaporation. The thickness of mesoporous $\mathrm{TiO}_{2}$ and perovskite is $\sim 550 \mathrm{~nm}$, whereas 
241 the capping layer of perovskite is estimated to be $\sim 100 \mathrm{~nm}$. Bigger crystals of $\mathrm{TiO}_{2}$ in the capping layer assist in saturated light absorption, which enhances the external quantum efficiency (EQE) in the red-light range.

For a valid comparison of performance in terms of PCE and stability, we prepared new dopant-free HTMs based devices and standard devices with dopant using conventional Spiro246 OMeTAD (with additional additives, including $t$ BP and LiTFSI) as the HTM. The optimized 247 champion device efficiency for DPA-ANT-DPA and Spiro-OMeTAD HTMs and 248 corresponding photovoltaic performance parameters are shown in Fig. 3 and Table 2.

(a)

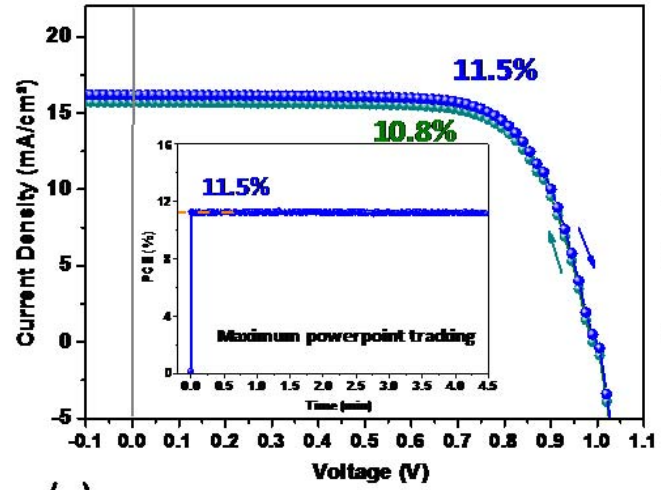

(c)

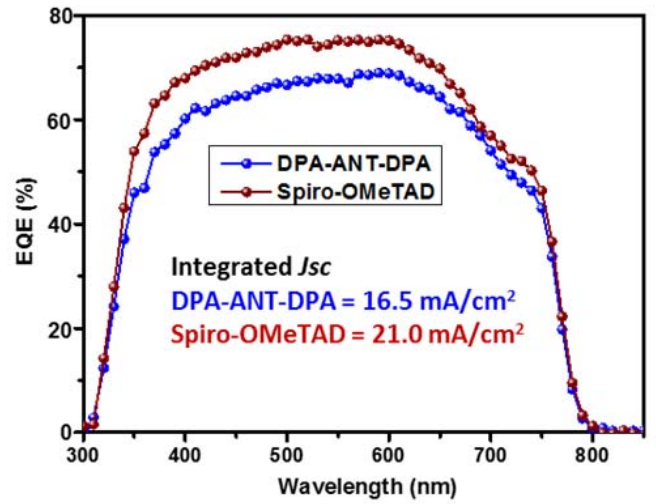

(b)

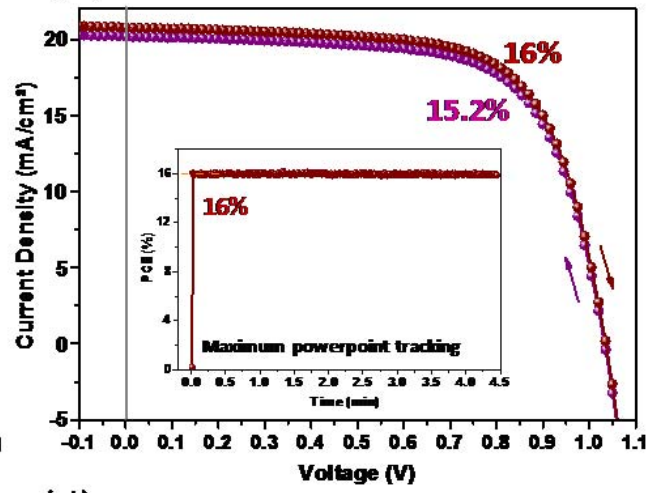

(d)

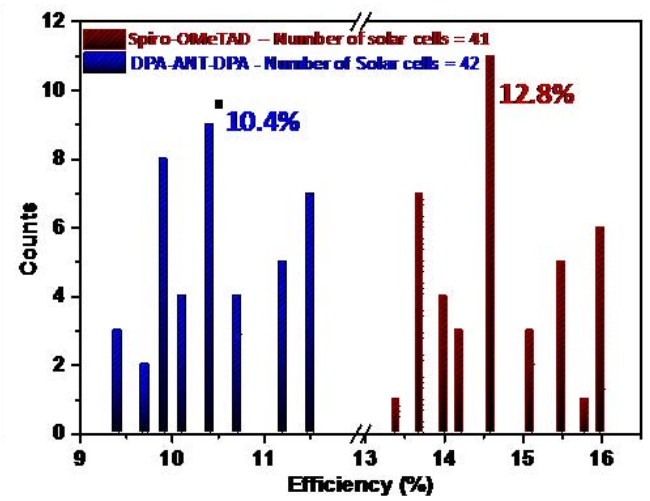

250 Fig. 3 Current-voltage scans for the best performing perovskite devices made using (a) DPA-

251 ANT-DPA as hole transport layer and (b) Spiro-OMeTAD as hole transport layer showing

252 PCEs $11.3 \%$ and $14.3 \%$ respectively. The full hysteresis loop is reported in Table 2 . The inset 253 shows the power output under maximum power point tracking for $270 \mathrm{~s}$, starting from 254 forward bias and resulting in a stabilized power output of $11.5 \%$ and $16 \%$ for DPA-ANT255 DPA and Spiro-OMeTAD hole transport based devices respectively. The constant scan rate 256 for all scans was $10 \mathrm{mV} \mathrm{s}-1$, (c) External quantum efficiency of perovskite devices prepared 257 using DPA-ANT-DPA and Spiro-OMeTAD hole transport materials. The integrated short 
258 circuit current density of $16.5 \mathrm{~mA} / \mathrm{cm}^{2}$ and $21 \mathrm{~mA} / \mathrm{cm}^{2}$ follows the JV scans from the solar

259 simulator, (d) Statistics, and the average device efficiency of a total of 83 solar cells prepared

260 using DPA-ANT-DPA and Spiro-OMeTAD as hole transport materials.

261

262 The non-doped DPA-ANT-DPA HTM based PSC devices (Fig. 3a) shows the highest 263 champion device efficiency of $11.5 \%\left(J_{\mathrm{sc}}=16.2 \mathrm{~mA} \mathrm{~cm}{ }^{-2}, V_{\mathrm{oc}}=1.0 \mathrm{~V}\right.$ and $\left.F F=71 \%\right)$.

264 Whereas the doped Spiro-OMeTAD-based device performance (Fig. 3b) approaches a PCE

265 of $16 \%$ with $J_{\text {sc }}$ of $21 \mathrm{~mA} \mathrm{~cm}^{-2}, V_{\mathrm{oc}}=1.03 \mathrm{~V}$ and $F F=74 \%$. The hysteresis behaviour of

266 champion devices and statistics of the total of 42 devices prepared using DPA-ANT-DPA and

26741 devices using Spiro-OMeTAD as hole transporting layers is shown in Table 2 and Fig.

268 3(a),(b) respectively.

269 Table 2 Solar cell device performance with DPA-ANT-DPA HTMs.

\begin{tabular}{|c|c|c|c|c|c|}
\hline HTLs & $\begin{array}{c}\text { Scan } \\
\text { Direction }\end{array}$ & $\mathrm{V}_{\mathrm{oc}}(\mathrm{V})$ & $\mathrm{J}_{\mathrm{Sc}}\left(\mathrm{mA} / \mathrm{cm}^{2}\right)$ & $\begin{array}{l}\mathrm{FF} \\
(\%)\end{array}$ & PCE $(\%)$ \\
\hline \multirow{3}{*}{ DPA-ANT-DPA ${ }^{\text {b) }}$} & Forward & 1.00 & 16.2 & 71 & 11.5 \\
\hline & Reverse & 0.98 & 15.8 & 69 & 10.8 \\
\hline & Average $^{\mathrm{d})}$ & 0.97 & 15.0 & 69 & 10.4 \\
\hline \multirow{3}{*}{ Spiro-OMeTAD ${ }^{\mathrm{c})}$} & Forward & 1.03 & 21.0 & 74 & 16.0 \\
\hline & Reverse & 1.03 & 20.4 & 72 & 15.2 \\
\hline & Average $^{\mathrm{d})}$ & 0.99 & 18.2 & 71 & 12.8 \\
\hline
\end{tabular}

270 a) Cell size (active area): $0.100 \mathrm{~cm}^{2}$. Photovoltaic performance at $1000 \mathrm{wm}^{-2}$ (AM1.5G) and constant scan speed 271 of $10 \mathrm{mV} \mathrm{s}^{-1}$ mesoscopic $\mathrm{CH}_{3} \mathrm{NH}_{3} \mathrm{PbI}_{3}$ devices; b) without additives; ${ }^{\mathrm{c})}$ with additives: 4-tert-butylpyridine $(t \mathrm{BP})$

272 and Li-bis(trifluoromethanesulfonyl)-imide (LiTFSI); ${ }^{\mathrm{d}} \mathrm{An}$ average device efficiency of a total of 41 and 42 273 devices for Spiro-OMeTAD and DPA-ANT-DPA, respectively. 
275 We observed a negligible hysteresis on the reverse scan $\left(0 \mathrm{~V}\right.$ to $\left.V_{\text {oc }}\right)$ at a low scan speed of 10 $276 \mathrm{mV} \mathrm{s}^{-1}$ for DPA-ANT-DPA and Spiro-OMeTAD based devices that results in the efficiency 277 decrease from $16 \%$ to $15.2 \%$ for Spiro-OMeTAD based and $11.5 \%$ to $10.8 \%$ for DPA-ANT278 DPA HTM based perovskite solar cells. The excessively small band offset of the HOMO 279 between perovskite and DPA-ANT-DPA HTL (as shown in Fig. 2(a)), may hamper the 280 effective hole transport ability. ${ }^{38}$ We observed that even though the work function of DPA281 ANT-DPA is very close to that of the perovskite active layer, a respectable PCE could still be 282 achieved, without doping. The good comparable $V_{\text {oc }}$ of $1.0 \mathrm{~V}$ for DPA-ANT-DPA to that of 283 Spiro-OMeTAD based devices is due to the very small band offset and HOMO value 284 difference between this compound and perovskite active layer. ${ }^{38}$ Furthermore, the non-doped 285 DPA-ANT-TPA based PSC shows a short circuit current $\left(J_{\mathrm{sc}}=16.2 \mathrm{~mA} \mathrm{~cm}^{-2}\right)$ comparable to 286 that with Spiro-OMeTAD $\left(J_{\mathrm{sc}}=21 \mathrm{~mA} \mathrm{~cm}{ }^{-2}\right)$ which is due to the shallower HOMO of DPA287 ANT-DPA that allows for effective hole extraction.

288 The PCE of $11.5 \%$, obtained using non-doped DPA-ANT-DPA HTM, is high compared to 289 other HTMs reported in the literature taking dopant-free aspect into account. ${ }^{49-41}$ As shown 290 in Fig. 3c, the devices with DPA-ANT-DPA exhibit external quantum efficiency (EQE) 291 values above 65 to $70 \%$ from $365 \mathrm{~nm}$ to $650 \mathrm{~nm}$ covering the entire UV region with the 292 highest EQE of $70 \%$ observed at $470 \mathrm{~nm}$. The statistics of total 83 PSCs prepared using 293 DPA-ANT-DPA and Spiro-OMeTAD as shown in Fig. 3d exhibits an average device 294 efficiency of $10.4 \%$ and $12.8 \%$ respectively.

(a)

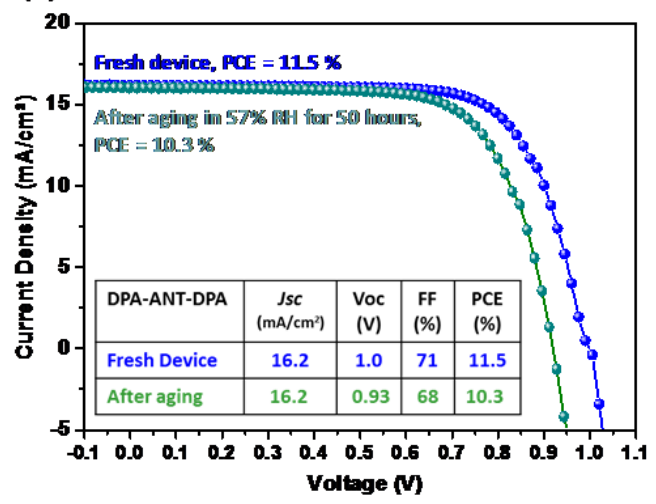

(b)

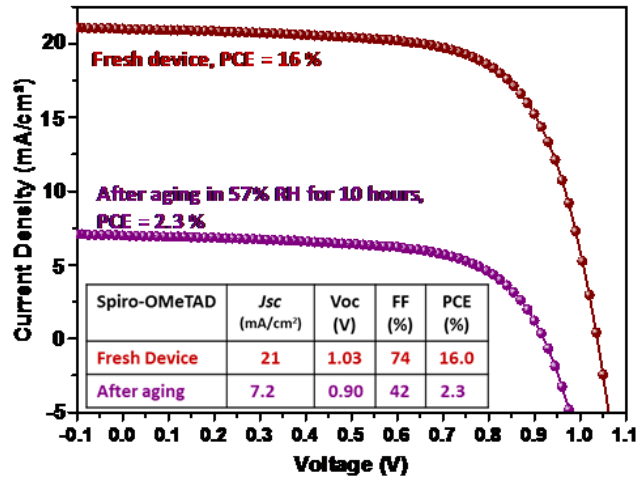

295

296 Fig. 4 Photovoltaic performance of DPA-ANT-DPA (a), and Spiro-OMeTAD (b) based $297 \mathrm{CH}_{3} \mathrm{NH}_{3} \mathrm{PbI}_{3}$ PSC devices respectively on aging in humidity $\geq 57 \%$ (the fresh and aged PSC 298 299 devices performance is shown in satellite table); Stability test/aging for 50 hours for DPAANT-DPA HTM based cells and 10 hours for Spiro-OMeTAD HTM based PSC: without 
encapsulation. After each consecutive measurement, the PSCs are kept in an ambient humidity setup of RH of $57 \%$, Temperature $=22{ }^{\circ} \mathrm{C}$.

The stability of PSCs is one of the most discussed issues within the perovskite solar cell community and a major hurdle for commercialization. Since the active layer in perovskite devices is an organometallic salt, it has a strong tendency to absorb water. Among different degradation factors, ambient humidity is one of the most critical parameters being for the degradation of Spiro-OMeTAD based PSCs and this is due to the hydrophilic nature of the active layer used in PSC. ${ }^{42-44}$ Taking these parameters into account, we studied the stability of fabricated champion devices without any encapsulation at high humidity conditions (relative humidity $(\mathrm{RH})=57 \%$, temperature $=22{ }^{\circ} \mathrm{C}$, in dark condition) for our newly developed DPA-ANT-DPA and standard Spiro-OMeTAD HTMs (as shown in Fig. 4).

A simple stability setup used is shown in Fig. S8 a,b (ESI†) and the photovoltaic 313 performance was measured at $1000 \mathrm{wm}^{-2}$ (AM1.5G) using regular aging intervals. The 314 photovoltaic properties of our novel DPA-ANT-DPA and Spiro-OMeTAD in the aging test 315 are detailed in Fig. 4a and 4b. Additionally, the efficiency of all HTMs based devices is 316 evaluated under identical conditions and depicted in Fig. 4. The degradation test results show 317 that the Spiro-OMeTAD HTM based devices degraded at a faster rate compared to DPA318 ANT-DPA based devices. The Spiro-OMeTAD HTM based devices showed a rapid drop in 319 PCE from $14.2 \%$ (Fresh device) to $2.3 \%$ after aging in $57 \% \mathrm{RH}$, for only 10 hours. Spiro320 OMeTAD HTM based devices showed significant drop in current from $J_{s c}=21$ to 7.1 $321 \mathrm{~mA} / \mathrm{cm}^{2}$. On the other hand, the DPA-ANT-DPA HTM based devices maintained the $J_{S c}$ of $32216 \mathrm{~mA} / \mathrm{cm}^{2}$ with a very small drop in open circuit voltage $V_{o c}$ from 1.0 to $0.93 \mathrm{~V}$. This 323 resulted in a small drop in PCE from $11.5 \%$ to $10.3 \%$, this is even after prolonged exposure 324 of 50 hours to high relative humidity of $57 \%$. This clearly shows improved device stability of 325 PSCs made using DPA-ANT-DPA HTM over Spiro-OMeTAD based devices.

\section{(a)}

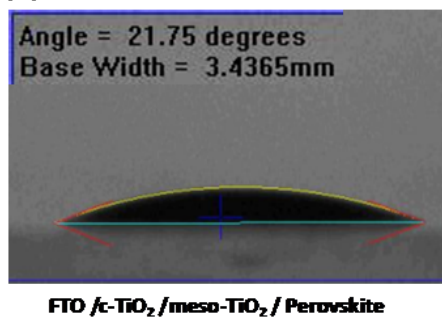

(b)

Angle $=47.97$ degrees

Base Width $=3.5749 \mathrm{~mm}$ (c)

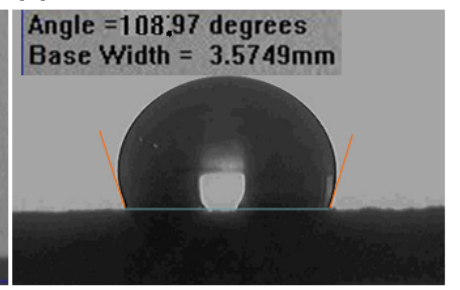


327 Fig. 5 Contact angle measurements performed on (a) $\mathrm{CH}_{3} \mathrm{NH}_{3} \mathrm{PbI}_{3}$ perovskite, (b) Spiro-

328 OMeTAD and (c) DPA-ANT-DPA surface, deposited on $\mathrm{FTO} / \mathrm{c}-\mathrm{TiO}_{2} / \mathrm{meso}^{-\mathrm{TiO}_{2}}$ substrate.

330 To further investigate the reason for the dramatic improvement in stability of DPA-ANT-

331 DPA (compare to Spiro-OMeTAD) based PSCs. Considering that the top layer of the 332 perovskite solar cell device plays an important role in preventing water ingress, ${ }^{45}$ we 333 performed contact angle measurements (as shown in Fig. 5(a-c)) as well morphological 334 measurements on the top surface of PSCs, which is the surface of HTMs (as shown in Fig. 6).

335 Fig. 5 (a) shows a low contact angle of $21^{\circ}$ of a water droplet on $\mathrm{CH}_{3} \mathrm{NH}_{3} \mathrm{PbI}_{3}$ surface, this 336 confirms the good wetting behaviour, high hydrophilic nature of the $\mathrm{CH}_{3} \mathrm{NH}_{3} \mathrm{PbI}_{3}$ perovskite 337 active layer used in this study. Doped Spiro-OMeTAD layers, deposited on top of the 338 perovskite shows a contact angle of $47.9^{\circ}$, indicating a reduced albeit still high degree of 339 hydrophilicity of the overall device. Snaith et al already demonstrated the cause behind 340 hydrophilic nature of Spiro-OMeTAD based HTM devices and this is mainly due to the 341 doping of Spiro-OMeTAD using hygroscopic LiTFSI salts. ${ }^{45}$ We would like to make clear 342 that though the Spiro-OMeTAD molecule itself is non-polar by nature due to the presence of 343 four methoxy groups on phenylene units, it becomes hydrophilic owing to the addition of 344 dopant salts. The contact angle measured using our newly developed DPA-ANT-DPA HTMs 345 surface without using any dopant leads to an impressive elevated contact angle of $108^{\circ}$ with 346 lower wetting (enhancing hydrophobicity); this is likely mainly responsible for higher 347 stability of reported devices here using our new HTM.

348 Moreover, it is further necessary to study the surface morphology of the HTMs in order to 349 understand the different wetting, de-wetting behaviour and hence to probe the reason for the 350 hygroscopic nature of the films. Fig. 6 shows surface morphology of the perovskite, DPA351 ANT-DPA and Spiro-OMeTAD hole transport layer. The $\mathrm{CH}_{3} \mathrm{NH}_{3} \mathrm{PbI}_{3}$ perovskite film Fig. 6 352 (a) shows good quality, larger crystalline grains ranging from $500-800 \mathrm{~nm}$. The good quality 353 of the perovskite film is further confirmed from high photoluminescence (PL) intensity 354 obtained (Fig. 7). The HTM DPA-ANT-DPA deposited on perovskite shows homogeneous, 355 uniform surface coverage over a large area (Fig. 6(b)), while the Spiro-OMeTAD deposited 356 on perovskite shows inhomogeneous and rough surface also formation of small aggregates at 357 intervals, as shown in Fig. 6(b-c). These are possibly the crystals formed due to doping of 358 LiTFSI. $^{46}$ This is further confirmed from the observation that in absence of doping with 
359 tertiary butyl pyridine $(t B P)$ and LiTFSI salts in Spiro-OMeTAD, we have not observed such 360 aggregate formation.
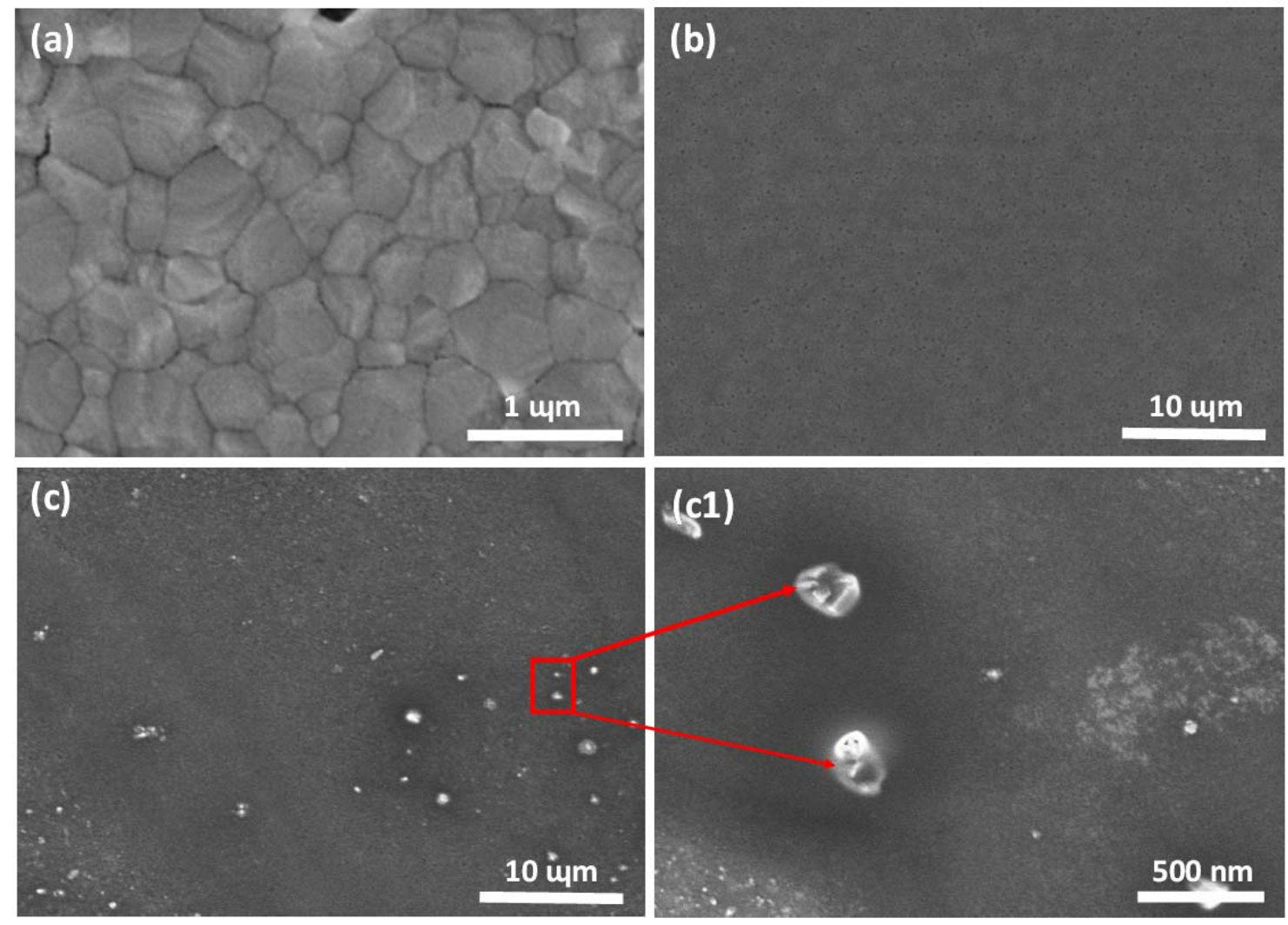

362 Fig. 6 (a) Surface image of $\mathrm{CH}_{3} \mathrm{NH}_{3} \mathrm{PbI}_{3}$ perovskite film deposited on top of FTO/compact-

$363 \mathrm{TiO}_{2} /$ mesoporous-TiO 2 ; (b) Top view of DPA-ANT-DPA on perovskite layer; (c) top view of

364 Spiro-OMeTAD on perovskite, and (c1) zoomed in of top view of Spiro-OMeTAD layer, red

365 mark highlights crystals formed due to addition of dopant. To mimics the device architecture

366 all the layers are deposited on $\mathrm{FTO} /$ compact- $\mathrm{TiO}_{2} /$ mesoporous- $^{-\mathrm{TiO}_{2}}$ substrate.

368 These electron microscope observations along with the contact angle measurements clearly 369 correlate with the higher perovskite solar cell stability observed for DPA-ANT-DPA HTM

370 based solar cells as compared to Spiro-OMeTAD HTM based solar cells. The improved 371 homogeneous coverage of the DPA-ANT-DPA films along with de-wetting, hydrophobic 372 nature as observed from contact angle measurements resulted in devices with much higher 373 stability, whereas the Spiro-OMeTAD HTM films with rough, in-homogeneous surface, 374 small to large pin-holes and increased wetting and hydrophilic nature exhibited lower 375 stability. The good coverage along with hydrophobic nature of the DPA-ANT-DPA HTM on 
376 the perovskite layer assures protection of the perovskite thin film layer from exposure to 377 oxygen, ${ }^{44,}{ }^{45}$ humidity, ${ }^{43}$ and heat. ${ }^{47}$ In summary, the homogeneous surface morphology and 378 de-wetting characteristics offered by the novel anthanthrone (ANT) core with extended 379 Diphenylamine (DPA) in DPA-ANT-DPA films have contributed significantly to protecting 380 the underneath perovskite layer from degradation.

(a)

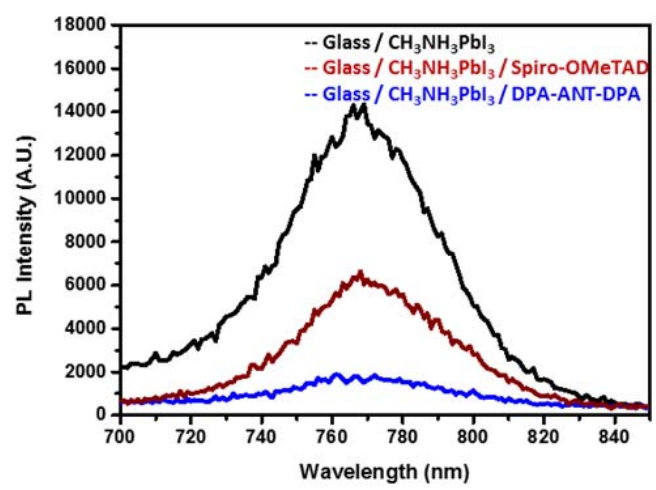

(b)

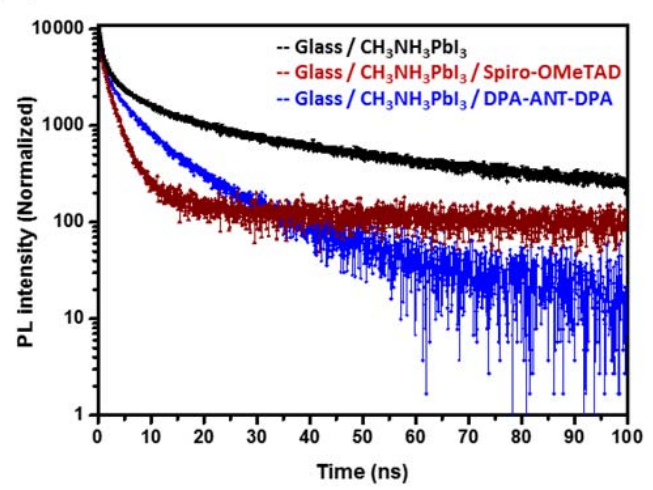

381

382 Fig. 7 (a) Steady state Photoluminescence (PL) measured on bare perovskite film (black), and 383 hole transport layer deposited on the perovskite. Brown curve represent Spiro-OMeTAD, blue curve represents DPA-ANT-DPA, respectively, deposited on perovskite. (b) Time resolved PL taken at excitation wavelength of $765 \mathrm{~nm}$ of the perovskite films with different hole transport layers. A $5 \mathrm{~mW}$ picosecond pulsed diode laser at $635 \mathrm{~nm}$ was used to irradiate the perovskite and hole transport layer side.

Steady state and time resolved photoluminescence based on a simple architecture: Glass $/ \mathrm{CH}_{3} \mathrm{NH}_{3} \mathrm{PbI}_{3} / \mathrm{HTM}$ is shown in Fig. 7. In order to eliminate any quenching effect related to electron transfer to the oxide layer, we avoided to use of a $\mathrm{TiO}_{2}$ layer while doing PL measurements. During these PL measurements, we have to make sure that the photoluminescence quenching is only caused by the hole transport layer and is not due to any other materials. All the HTL thin films were excited at $635 \mathrm{~nm}$ wavelength. From the data, it is quite clear that the bare perovskite film without any HTM (black curve) exhibits a high PL emission intensity as a result of the formation of good quality (crystallinity and homogeneous surface) perovskite film, which is also seen from the surface morphology of the perovskite film (Fig. 6a). On deposition of HTM on the perovskite layer, a significant reduction in PL emission was observed. Perovskite films covered with DPA-ANT-DPA HTL (blue curve) 
400 display a stronger PL quenching ( $90 \%)$ than the films covered with Spiro-OMeTAD $(\sim 60 \%)$

401 HTL. This effective quenching indicates a higher PL quenching ability of our newly developed DPA-ANT-TPA compared to Spiro-OMeTAD. The DPA-ANT-DPA HTM exhibits efficient exciton dissociation efficiency, comparable to that of doped SpiroOMeTAD. This ensures a efficient charge generation and high hole mobility as well as low recombination at the DPA-ANT-DPA/CH $3 \mathrm{NH}_{3} \mathrm{PbI}_{3}$ interface.

The time resolved photoluminescence was performed to verify the improved hole transport properties; the results are shown in Fig. 7b. Bare perovskite films deposited on glass substrate as well as with different hole transport layers show biphasic kinetics. The fast component decays in picoseconds (due to 80 ps laser pulse) and the slower component has a time constant of 10-15 ns. The fast component represents trap filling. As the hole transfer films are deposited on bare glass - perovskite layer for direct probing, this gives us a good estimation of quenching of the photoluminescence due to hole transport layers only.

413 For bare perovskite sample (glass/perovskite) we have obtained high PL intensity and 414 lifetime of $8 \mathrm{~ns}$. As shown previously ${ }^{48}$ highly crystalline, good quality perovskite sample 415 shows a life time of $\sim 8-10 \mathrm{~ns}$, this confirms the quality of the perovskite films we used in 416 this study. After the introduction of DPA-ANT-DPA hole transporting layer above the 417 perovskite layer the average decay time $(T)$ shortened to $20.2 \mathrm{~ns}$. The fast decay lifetime $418\left(T_{1}\right)$ of both hole transporting materials decreased from $33 \mathrm{~ns}$ (bare perovskite without HTL) 419 to $18 \mathrm{~ns}$ for DPA-ANT-DPA and $16 \mathrm{~ns}$ for Spiro-OMeTAD hole transporting layer. At the same time the weight fraction increased from 3\% (bare perovskite film) to $23.5 \%$ for DPAANT-DPA and $25.7 \%$ for Spiro-OMeTAD hole transport layers. This clearly shows the complete hole extraction as well charge dissociation exerted by our novel undoped DPAANT-DPA HTM is competent the traditional doped Spiro-OMeTAD.

424 Currently, among reported competitive D-A-D type HTMs in the literature using both 425 planar and mesoporous devices, JY5 and JY6 HTMs in planar devices ${ }^{16,17}$ and BTPA-3 and 426 H1 HTMs based mesoporous layouts exhibit lower performance. ${ }^{6,15}$ A brief comparison 427 based on the similar device structure and approximately equivalent working area among our 428 new HTM, DPA-ANT-DPA, with BTPA-3 and H1 is made and shown in Table 3. Overall, 429 the photovoltaic performance of DPA-ANT-DPA based devices achieves the highest PCE of $43011.5 \%$ among all these materials without any additives, whereas the BTPA-3-based device 431 exhibits a close PCE of 9.81\% with Li-TFSI and $t$ BP as dopants. Notably, though the novel 432 DPA-ANT-DPA and H1 have the similar HOMO energy levels, the PCE of H1 based devices 
433 is very low $(\sim 5.8 \%)$ due to its small $J_{s c}$ and the use of different type of perovskite as active 434 layers. Moreover, the device with new DPA-ANT-DPA HTM has a superior stability in 435 comparison with the reference device based on Spiro-OMeTAD.

436 Table 3. The comparison among promising D-A-D HTMs.

\begin{tabular}{|c|c|c|c|c|c|c|c|c|c|c|}
\hline HTM $^{\text {a) }}$ & $\begin{array}{c}\text { HOMO } \\
(\mathrm{eV})\end{array}$ & Perovskite materials & $\begin{array}{l}\text { Active } \\
\text { area } \\
\left(\mathrm{cm}^{2}\right)\end{array}$ & Additives $^{\text {b) }}$ & $\begin{array}{l}\mathrm{V}_{\text {oc }} \\
\text { (V) }\end{array}$ & $\begin{array}{c}\mathrm{J}_{\mathrm{sc}} \\
(\mathrm{mA} \\
\left.\mathbf{c m}^{-2}\right)\end{array}$ & $\begin{array}{l}\text { FF } \\
(\%)\end{array}$ & $\begin{array}{l}\text { PCE } \\
(\%)\end{array}$ & $\begin{array}{c}\text { Stability } \\
\text { test }^{\mathrm{d})}\end{array}$ & References \\
\hline $\begin{array}{l}\text { DPA- } \\
\text { ANT- } \\
\text { DPA }\end{array}$ & -5.46 & $\mathrm{CH}_{3} \mathrm{NH}_{3} \mathrm{PbI}_{3}$ & 0.1 & None & 1.00 & 16.2 & 71 & $\begin{array}{c}11.5 \\
(16.0)^{\mathrm{c}}\end{array}$ & $\begin{array}{c}66 \% \\
(14 \%)^{\mathrm{e}}\end{array}$ & This study \\
\hline BTPA-3 & -5.42 & $\begin{array}{l}\mathrm{Cs}_{0.05}\left(\mathrm{MA}_{0.17} \mathrm{FA}_{0.83}\right)_{0.95} \mathrm{~Pb}\left(\mathrm{I}_{0.83} \mathrm{Br}_{0.17}\right)_{3} \\
\end{array}$ & 0.16 & $\begin{array}{c}\text { Li-TFSI } \\
t \mathrm{BP}\end{array}$ & 1.09 & 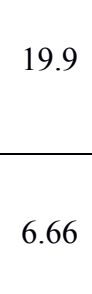 & 53.4 & $\begin{array}{c}9.81 \\
(13.2) \\
5.91 \\
(5.61)\end{array}$ & $\begin{array}{c}84 \% \\
(98 \%) \\
75 \% \\
(91 \%)\end{array}$ & 6 \\
\hline H1 & -5.46 & $\mathrm{CH}_{3} \mathrm{NH}_{3} \mathrm{PbBr}_{3}$ & 0.16 & $\begin{array}{l}\text { Li-TFSI } \\
\qquad \begin{array}{l}t \text { BP } \\
\text { FK209 }\end{array}\end{array}$ & 1.43 & 5.50 & 72 & $\begin{array}{c}5.80 \\
(6.12)\end{array}$ & - & 15 \\
\hline
\end{tabular}

$437{ }^{\text {a) }}$ A typical mesoporous architecture, including FTO/compact $\mathrm{TiO}_{2} /$ mesoporous $\mathrm{TiO}_{2} /$ Perovskite/HTM/cathode, 438 was used in these studies. While Ag was the cathode in this study, Au were employed in other citations (H1, 439 BTPA-3).

$440 \quad{ }^{b}$ bis(trifluoromethylsulfonyl)imide lithium salt (Li-TFSI), 4-tert-Butylpyridine ( $t$ BP), tris(2-(1H-pyrazol-1-yl)-

441 4-tert-butylpyridine)cobalt(III) tri[hexafluorophosphate] (FK209)

$442{ }^{\mathrm{c})}$ PCE of standard Spiro-OMeTAD

$443{ }^{\mathrm{d})}$ The percentage of the retaining performance after the ageing test (unsealed devices)

$44{ }^{\mathrm{e})}$ The percentage of the retaining performance of standard Spiro-OMeTAD

445

\section{Conclusions}

447 In summary, we have successfully designed and synthesized a new highly scalable 448 small molecular DPA-ANT-DPA HTM based on an innovative low cost anthanthrone 449 dye as a core using D-A-D molecular design. The synthesis of DPA-ANT-DPA was 
450 elegantly conducted in a single step via a simple coupling protocol using a common 451 anthanthrone dye as a central core and diphenylamine as end-capping units. A detailed 452 comparison on optoelectronic properties of DPA-ANT-DPA and traditional Spiro453 OMeTAD based PSCs has been performed and it has found that a HOMO energy level 454 of DPA-ANT-DPA is close to the active perovskite energy level, guaranteeing a better 455 hole transport ability with minimal energy offset. Upon evaluating DPA-ANT-DPA as 456 hole transporting material, without doping in perovskite solar cell devices, the highest 457 power conversion efficiency of $11.5 \%$ has been achieved. The DPA-ANT-DPA HTM 458 not only exhibits a respectable performance in comparison to other undoped hole 459 transport materials, but shows also an increased reproducibility of PSCs as compared 460 to Spiro-OMeTAD based PSCs and a lower cost and straightforward one-step 461 synthesis with easy purification. One of the most important features of DPA-ANT462 DPA based PSC devices is their environmental stability, much higher than that of 463 classical Spiro-OMeTAD. The reason behind the significantly higher stability of our 464 new DPA-ANT-DPA based devices has been also investigated in detail and it was

465 found that the hydrophobic nature and homogeneous coverage are responsible factors 466 and they are a result of chemical structure of the central ANT core and more extended 467 structure of DPA on the perovskite capping layer. The DPA-ANT-DPA HTM without 468 additives resulted in $V_{o c}$ of $1.0 \mathrm{~V}$. The improved charge collection efficiency in devices 469 prepared with DPA-ANT-DPA HTL (as seen from effective PL quenching) compared 470 to that of the Spiro-OMeTAD HTL leads to higher short circuit current and 471 photovoltage. By using such low cost fused anthanthrone dye, it is be possible to 472 design new efficient, stable and low cost scalable HTMs for roll-to-roll printed 473 perovskite solar cell modules and prototypes for large area application.

\section{Experimental}

476 Detailed experimental methods can be found in the Supporting Information.

\section{Conflicts of interest}

479 There are no conflicts to declare.

\section{Acknowledgements}


481 H.D.P is thankful to QUT for offering here QUTPRA scholarship to conduct his research 482 work. Some of the data reported in this paper were obtained at the Central Analytical 483 Research Facility operated by the Institute for Future Environments (QUT). Access to CARF 484 is supported by generous funding from the Science and Engineering Faculty (QUT). Author 485 S. M. J. is thankful to Welsh assembly Government funded Sêr Cymru Solar project, EPSRC 486 grants EP/M025020/1 (Supergen Solar Challenge) and Marie-Curie COFUND fellowship for 487 financial support. S.M. is supported by the Ministry of Education of Singapore. Additionally, 488 this project has received funding from the European Union's Horizon 2020 research and 489 innovation programme under the Marie Skłodowska-Curie grant agreement No 663830. P.S. 490 is thankful to QUT for financial support and to the Australian Research Council for the 491 Future Fellowship grant FT130101337. N.M. acknowledges the support of the Queensland 492 government via the Q-CAS funding scheme.

493 


\section{References}

496 1. Best research-cell efficiencies, http://www.nrel.gov/pv/assests/images/efficiency$497 \quad$ chart.png (accessed: Novemeber 2017).

498 2. W. S. Yang, B.-W. Park, E. H. Jung, N. J. Jeon, Y. C. Kim, D. U. Lee, S. S. Shin, J. 499 Seo, E. K. Kim, J. H. Noh and S. I. Seok, Science, 2017, 356, 1376-1379.

500 3. N. H. Tiep, Z. Ku and H. J. Fan, Adv. Energy Mater., 2016, 6, 1501420.

501 4. Y.-K. Wang, Z.-C. Yuan, G.-Z. Shi, Y.-X. Li, Q. Li, F. Hui, B.-Q. Sun, Z.-Q. Jiang 502 and L.-S. Liao, Adv. Funct. Mater., 2016, 26, 1375-1381.

5. K. Liu, Y. Yao, J. Wang, L. Zhu, M. Sun, B. Ren, L. Xie, Y. Luo, Q. Meng and X. 504 Zhan, Mater. Chem. Front., 2017, 1, 100-110.

6. G. Wu, Y. Zhang, R. Kaneko, Y. Kojima, Q. Shen, A. Islam, K. Sugawa and J. Otsuki, J. Phys. Chem. C, 2017, 121, 17617-17624.

7. H. D. Pham, H. Hu, K. Feron, S. Manzhos, H. Wang, Y. M. Lam and P. Sonar, Solar $R R L, 2017,1$.

8. J. Wang, K. Liu, L. Ma and X. Zhan, Chem. Rev., 2016, 116, 14675-14725.

10. H. D. Pham, Z. Wu, L. K. Ono, S. Manzhos, K. Feron, N. Motta, Y. Qi and P. Sonar, Adv. Electronic Mater., 2017, 3.

11. M. Saliba, S. Orlandi, T. Matsui, S. Aghazada, M. Cavazzini, J.-P. Correa-Baena, P. Gao, R. Scopelliti, E. Mosconi, K.-H. Dahmen, F. De Angelis, A. Abate, A. Hagfeldt, G. Pozzi, M. Graetzel and M. K. Nazeeruddin, Nat. Energy, 2016, 1, 15017-15024.

12. S. S. Reddy, S. Shin, U. K. Aryal, R. Nishikubo, A. Saeki, M. Song and S.-H. Jin, Nano Energy, 2017, 41, 10-17.

13. M. Cheng, K. Aitola, C. Chen, F. Zhang, P. Liu, K. Sveinbjörnsson, Y. Hua, L. Kloo, G. Boschloo and L. Sun, Nano Energy, 2016, 30, 387-397.

14. K. Rakstys, S. Paek, P. Gao, P. Gratia, T. Marszalek, G. Grancini, K. T. Cho, K. Genevicius, V. Jankauskas, W. Pisula and M. K. Nazeeruddin, J. Mater. Chem. A, 2017, 5, 7811-7815.

15. S. Carli, J. P. Baena, G. Marianetti, N. Marchetti, M. Lessi, A. Abate, S. Caramori, M. Gratzel, F. Bellina, C. A. Bignozzi and A. Hagfeldt, ChemSusChem., 2016, 9, 657661.

16. F. Wu, Y. Ji, R. Wang, Y. Shan and L. Zhu, Dyes Pigm., 2017, 143, 356-360.

17. F. Wu, Y. Ji, C. Zhong, Y. Liu, L. Tan and L. Zhu, Chem. Commun., 2017, 53, 87198722.

18. J. M. Jiang, P. A. Yang, H. C. Chen and K. H. Wei, Chem. Commun., 2011, 47, 88778879.

19. P. Ganesan, K. Fu, P. Gao, I. Raabe, K. Schenk, R. Scopelliti, J. Luo, L. H. Wong, M. Grätzel and M. K. Nazeeruddin, Energy Environ. Sci., 2015, 8, 1986-1991.

20. S. Park, J. H. Heo, C. H. Cheon, H. Kim, S. H. Im and H. J. Son, J. Mater. Chem. A, $2015,3,24215-24220$. 
536 21. K. Do, H. Choi, K. Lim, H. Jo, J. W. Cho, M. K. Nazeeruddin and J. Ko, Chem. Commun., 2014, 50, 10971-10974.

538 22. Z. Tu, X. Huang and Y. Yi, J. Mater. Chem. C, 2015, 3, 1913-1921.

539 23. J. B. Giguere, J. Boismenu-Lavoie and J. F. Morin, J. Org. Chem., 2014, 79, $2404-$ 2418.

24. A. Lafleur-Lambert, J.-B. Giguère and J.-F. Morin, Macromolecules, 2015, 48, 83768381.

25. U. Koldemir, J. S. Tinkham, R. Johnson, B. Lim, H. A. Yemam, K. J. Gagnon, S. Parkin and A. Sellinger, J. Mater. Chem. C, 2017, 5, 8723-8733.

26. J. B. Giguere, Q. Verolet and J. F. Morin, Chem. Eur. J., 2013, 19, 372-381.

A. D. Becke, J. Chem. Phys., 1993, 98, 5648-5652.

28. P. Hohenberg and W. Kohn, Phys. Rev. , 1964, 136, B864-B871.

29. W. Kohn and L. Sham, Phys. Rev. , 1965, 140, A1133-A1138.

30. S. Paek, M. A. Rub, H. Choi, S. A. Kosa, K. A. Alamry, J. W. Cho, P. Gao, J. Ko, A.

31. F. M. Jradi, X. Kang, D. O’Neil, G. Pajares, Y. A. Getmanenko, P. Szymanski, T. C. Parker, M. A. El-Sayed and S. R. Marder, Chem. Mater., 2015, 27, 2480-2487.

32. P. Qin, H. Kast, M. K. Nazeeruddin, S. M. Zakeeruddin, A. Mishra, P. Bäuerle and M. Grätzel, Energy Environ. Sci., 2014, 7, 2981-2985.

33. C. Steck, M. Franckevičius, S. M. Zakeeruddin, A. Mishra, P. Bäuerlea and M. Grätzel, J. Mater. Chem. A, 2015, 3, 17738-17746.

34. K. Rakstys, M. Saliba, P. Gao, P. Gratia, E. Kamarauskas, S. Paek, V. Jankauskas and M. K. Nazeeruddin, Angew. Chem. Int. Ed. Engl., 2016, 55, 1-6.

35. D. Shi, X. Qin, Y. Li, Y. He, C. Zhong, J. Pan, H. Dong, W. Xu, T. Li, W. Hu, J.-L. Brédas and O. M. Bakr, Sci. Adv., 2016, 2, e1501491.

36. S. Paek, P. Qin, Y. Lee, K. T. Cho, P. Gao, G. Grancini, E. Oveisi, P. Gratia, K. Rakstys, S. A. Al-Muhtaseb, C. Ludwig, J. Ko and M. K. Nazeeruddin, Adv. Mater., 2017, 29, 1606555.

37. N. J. Jeon, J. H. Noh, Y. C. Kim, W. S. Yang, S. Ryu and S. I. Seok, Nat. Mater., 2014, 13, 897-903.

38. W.-J. Yin, J.-H. Yang, J. Kang, Y. Yan and S.-H. Wei, J. Mater. Chem. A, 2015, 3, 8926-8942.

39. J. Liu, Y. Wu, C. Qin, X. Yang, T. Yasuda, A. Islam, K. Zhang, W. Peng, W. Chen and L. Han, Energy Environ. Sci., 2014, 7, 2963-2967.

40. S. Kazim, F. J. Ramos, P. Gao, M. K. Nazeeruddin, M. Grätzel and S. Ahmad, Energy Environ. Sci., 2015, 8, 1816-1823.

41. M. Franckevičius, A. Mishra, F. Kreuzer, J. Luo, S. M. Zakeeruddin and M. Grätzel, Mater. Horiz., 2015, 2, 613-618.

42. Y. Hou, H. Zhang, W. Chen, S. Chen, C. O. R. Quiroz, H. Azimi, A. Osvet, G. J. Matt, E. Zeira, J. Seuring, N. Kausch-Busies, W. Lövenich and C. J. Brabec, $A d v$. Energy Mater., 2015, 5, 1500543. 
577

578

579

580

581

582

583

584

585

586

587

588

589

590
43. J. S. Manser, M. I. Saidaminov, J. A. Christians, O. M. Bakr and P. V. Kamat, Acc. Chem. Res., 2016, 49, 330-338.

44. J. Yang, B. D.Siempelkamp, D. Liu and L. K. Timothy, ACS Nano, 2015, 9, 19551963.

45. T. Leijtens, T. Giovenzana, S. N. Habisreutinger, J. S. Tinkham, N. K. Noel, B. A. Kamino, G. Sadoughi, A. Sellinger and H. J. Snaith, ACS Appl. Mater. Interfaces, 2016, 8, 5981-5989.

46. B. Xu, J. Zhang, Y. Hua, P. Liu, L. Wang, C. Ruan, Y. Li, G. Boschloo, E. M. J. Johansson, L. Kloo, A. Hagfeldt, A. K. Y. Jen and L. Sun, Chem, 2017, 2, 676-687.

47. W. H. Nguyen, C. D. Bailie, E. L. Unger and M. D. McGehee, J. Am. Chem. Soc., 2014, 136, 10996-11001.

48. S. M. Jain, Z. Qiu, L. Häggman, M. Mirmohades, M. B. Johansson, T. Edvinsson and G. Boschloo, Energy Environ. Sci., 2016, 9, 3770-3782. 